\title{
Pengaruh Motivasi, Kepuasan Kerja Dan Disiplin Kerja Terhadap Kinerja Karyawan Di Pt Sari Dumai Sejati
}

\author{
1Juni, ${ }^{2}$ Ploran Togatorop \\ ${ }^{1}$ Staff Pengajar Program Studi Teknik Industri \\ ${ }^{2}$ Mahasiswa Program Studi Teknik Industri \\ Sekolah Tinggi Teknologi Dumai
}

\begin{abstract}
ABSTRAK
Penelitian ini bertujuan untuk menjelaskan variabel motivasi, kepuasan kerja dan disiplin kerja terhadap kinerja karyawan di PT Sari Dumai Sejati serta untuk mengetahui variabel independen secara serempak terhadap kinerja karyawan di PT Sari Dumai Sejati.Penentuan Sampel menggunakan rumus Slovin dengan populasi 198 orang dan sampel yang digunakan sebanyak 66 orang dengan metode pengumpulan data yaitu kuisioner tertutup. Penyelesaian penelitian ini menggunakan model regersi berganda uji $t$ dan uji f. Hasil penelitian ini menunjukan bahwa variabel motivasi, kepuasan kerja dan disiplin kerja secara serempak berpengaruh signifikan dan positif terhadap kinerja karyawan dengan koefisien determinasi (R2) dengan melihat Adjust Square sebesar 0,964.
\end{abstract}

Kata-Kunci: Disiplin kerja, kepuasan kerja, kinerja karyawan, motivasi

\section{Pendahuluan}

PT Sari Dumai Sejati merupakan salah satu eksportir minyak sawit di Indonesia, memiliki dan mengontrol nilai rantai bisnis kelapa sawit dari sumber untuk distribusi dan bergerak di bidang penyulingan, pengolahan dan perdagangan minyak sawit untuk keperluan rumah tangga dan ke ekspor internasional. PT Sari Dumai Sejati merupakan bagian dari Apical Grup untuk dowstream dan Asian Agri Group untuk upstream dibawah Rajawali Garuda Eagle Group, sebuah kelompok kelas dunia dari perusahaan yang berfokus pada industri kelapa sawit, dengan pengolahan akhir menjadi minyak makan, margarine dan lain-lain. Sebagai perusahaan yang bergerak dalam bidang pengolahan kelapa sawit, perusahaan banyak mempekerjakan karyawan agar kegiatan operasional perusahaan dapat berjalan dengan lancar.Karyawan merupakan faktor yang sangat penting dalam perkembangan perusahaan. Baik dan buruknya kinerja perusahaan dalam mencapai target, akan tergantung kepada kinerja karyawannya dalam bekerja. Ketika kinerja karyawan baik, maka perusahaan akan dapat mencapai target manajemen perusahaan. Oleh sebab itu sangat penting untuk mengontrol karyawan agar dapat memberikan kinerja yang baik.

Kinerja merupakan suatu fungsi motivasi dan kemampuan.Untuk meyelesaikan tugas dan pekerjaan seseorang sepatutnya memiliki rasa kesediaan dan tingkat kemampuan tertentu. Kesedian dan keterampilan seseorang tidaklah cukup efektif untuk mengerjakan sesuatu tanpa pemahaman yang jelas tentang apa yang dikerjakan dan bagaimana mengerjakannya. Kinerja merupakan pencapaian 
persyaratan perkerjaan tertentu yang akhirnya secara langsung dapat bercermin dari keluaran yang dihasilkan.Menurut Rivai (2006) kinerja merupakan perilaku nyata yang ditampilkan setiap orang sebagai prestasi kerja yang dihasilkan oleh pegawai sesuai dengan peranan dalam perusahaan. Namun antara harapan dan kenyataan tidaklah sama. Perusahaan memiliki permasalahan tersendiri yang berhubungan dengan karyawan.Kinerja karyawan dinilai kurang bagus. Hal ini ditandai dengan turunnya pencapaian target pemakaian bahan bakuCrude Palm Oil di Pabrik Refinery PT Sari Dumai Sejati

Tabel 1. Jumlah Pemakaian Bahan Baku Crude Palm Oil pada Pabrik Refinery PT. Sari Dumai Sejati Tahun 2010 Sampai dengan 2013

\begin{tabular}{|c|c|c|c|c|}
\hline \multirow[t]{2}{*}{ Tshnn } & \multicolumn{2}{|c|}{ Pomalaian Bahan Bis: (CPO-MT) } & \multirow[t]{2}{*}{ Variance } & \multirow[t]{2}{*}{$\%$} \\
\hline & Actual & Budgat & & \\
\hline 2010 & 783,730 & $1,020,000$ & $-236,220$ & -23.25 \\
\hline 2011 & 945,600 & $1,088,400$ & $-142,800$ & -13.15 \\
\hline 2012 & $1,269,214$ & $1,336,000$ & $-66,786$ & -5.95 \\
\hline 2013 & $1,993,577$ & $2,356,600$ & $-393,023$ & -16.54 \\
\hline
\end{tabular}

Sumber : PT. Sari Dumai Sejati (Apical Dumai 2014)

Tabel 1dapat dilihat belum pernah tercapai pemakaian bahan bakuCrude Palm Oil pada Refinery plant yang ditargetkan oleh perusahaan. Pada tahun 2010 aktual pemakaian bahan baku 783,780 ton dari 1,020,000 ton yang ditargetkan perusahaan (-23.2\%). Tahun 2011 aktual pemakaian bahan baku 945,600 ton dari 1,088,400 ton yang ditargetkan perusahaan (13.1\%). Tahun 2012 aktual pemakaian bahan baku 1,269,214 dari 1,336,000 ton yang di targetkan perusahaan (5.0\%). Tahun 2013 aktual pemakaian bahan baku $1,993,577$ ton dari $2,386,600$ ton dari yang ditargetkan perusahaan (-16.5\%).

Kinerja karyawan yang tidak sesuai harapan dapat diakibatkan dari berbagai faktor, seperti motivasi, kepuasaan kerja dan disiplin kerja (Listianto, 2006). Motivasi merupakan faktor yang menimbulkan semangat atau dorongan kerja dalam diri karyawan untuk melakukan sesuatu demi memperoleh apa yang menjadi kebutuhan karyawan dan untuk mencapai tujuan dari organisasi.Rendahnya motivasi karyawan disebabkan karena peluang untuk terus berkembang di perusahaan yang rendah sehingga rasa ingin mengembangkan dirinya menjadi lebih baik dan bekerja keras untuk mencapai keinginan menjadi lebih baik berkurang. Kepuasan kerja yang dimiliki oleh seorang karyawan akan memperlihatkan sikap yang positif terhadap pekerjaan dalam bekerja, sedangkan karyawan yang tidak puas akan memperlihatkan sikap yang negatif terhadap pekerjaan sendiri. Kepuasan kerja merupakan hasil dari berbagai sikap bagi seorang karyawan, jika suatu pekerjaan sesuai dengan kepentingan dan harapan maka semakin tinggi tingkat kepuasan yang dirasakan oleh karyawan demikian pula sebaliknya.

Disiplin kerja karyawan dapat dilihat dari kesadaran yang muncul dari dalam diri karyawan tanpa ada paksaan untuk mengikuti peraturan yang berlaku dalam suatu organisasi. Disiplin merupakan modal yang diperlukan dalam mencapai tujuan yang diinginkan, sehingga keberadaan disiplin kerja amat diperlukan dalam suatu perusahaan, karena dalam suasana disiplin sebuah organisasi atau instansi akan dapat melaksanakan program- program kerjanya mencapai sasaran yang telah ditetapkan.Kinerja adalah hasil kerja yang dapat dicapai oleh seseorang atau kelompok dalam suatu organisasi, sesuai dengan wewenang dan tanggungjawab 
masing-masing, dalam rangka mencapai tujuan organisasi bersangkutan secara legal, tidak melanggar hukum, dan sesuai dengan moral dan etika.

Berdasarkan uraian pada latar belakang, masalah penelitian ini adalah bagaimana kinerja karyawan PT Sari Dumai Sejati (Apical Group) yang bertujuan untuk mengetahui apakah terdapat pengaruh yang signifikan Motivasi kerja terhadap kinerja karyawan PT Sari Dumai Sejati (Apical Group), mengetahui apakah terdapat pengaruh yang signifikan Kepuasan kerja terhadap kinerja karyawan PT Sari Dumai Sejati (Apical Group), mengetahui apakah terdapat pengaruh yang signifikan Disiplin kerja terhadap kinerja karyawan PT Sari Dumai Sejati (Apical Group), dan mengetahui faktor apakah yang paling dominan terhadap kinerja karyawan PT Sari Dumai Sejati (Apical Group).

\section{Metode Penelitian}

Penelitian ini dilakukan di PT Sari Dumai Sejati Desa Lubuk Gaung kecamatan Sungai Sembilan Dumai Riau.Waktu penelitian dilaksanakan mulai bulan Juni 2015.Populasi dalam penelitian adalah karyawan PT Sari Dumai Sejati Dumai bagian produksi.Jumlah populasi penelitian ini sebanyak 198 orang.Banyaknya sampel dalam penelitian ini adalah sebanyak 66 orang berdasarkan rumus slovin.Penentuan besar sampel yang dianggap representatif, dengan menggunakan rumus Slovin (Umar, 2005).Teknik pengumpulan data dilakukan dengan: 1) wawancara kepada pihak yang berhak dan berwenang memberi data dan informasi tentang kinerja karyawan di PT Sari Dumai Sejati, 2) Daftar Pertanyaan (Kuesioner) yang diberikan kepada karyawan PT Sari Dumai Sejati yang dipilih menjadi sampel dengan menggunakan skala likert, 3) Studi Dokumentasi, dengan mengumpulkan dan mempelajari data serta informasi dari PT Sari Dumai Sejati. Diagram alir penelitian diperlihatkan pada Gambar 1. 


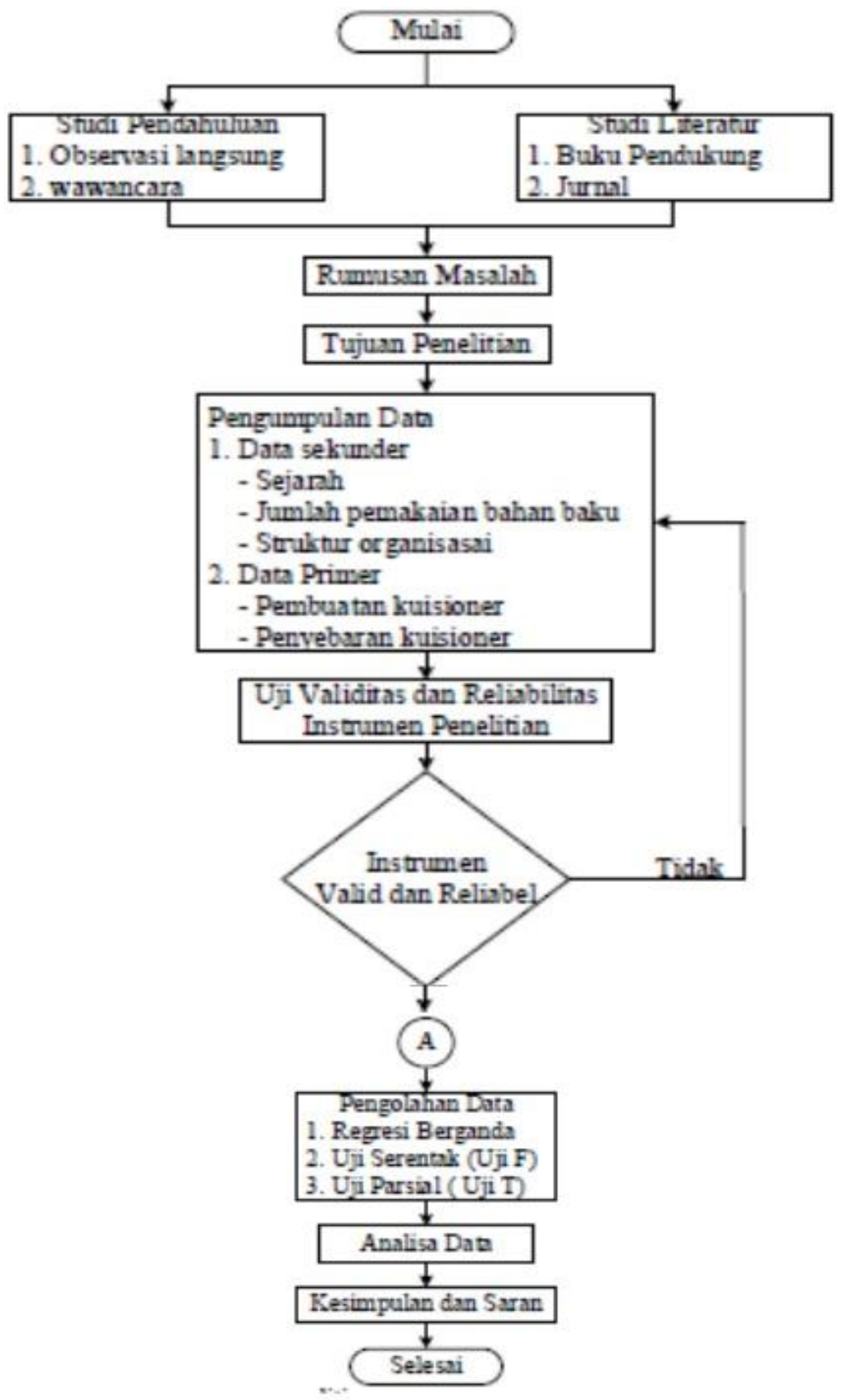

Gaambar 1. Diagram alir penelitian 


\section{Hasil dan Pembahasan}

Pengujian validitas.

Tabel 2. Pengujian validitas

\begin{tabular}{|c|c|c|c|c|}
\hline \multirow{2}{*}{ Variabel } & \multirow{2}{*}{ Pertanyaan } & \multirow{2}{*}{$\begin{array}{c}\text { Corrected } \\
\text { Item } \\
\text { Total } \\
\text { Comelation } \\
\end{array}$} & Nilai & \multirow{2}{*}{$\begin{array}{c}\text { Keteranga } \\
\text { n }\end{array}$} \\
\hline & & & $\begin{array}{c}\text { R- } \\
\text { Tabel }\end{array}$ & \\
\hline \multirow{6}{*}{$\begin{array}{c}\text { Motivasi } \\
\left(\mathrm{X}_{1}\right)\end{array}$} & Motivasi 1 & 0,487 & \multirow{6}{*}{0,238} & Valid \\
\hline & Motivasi 2 & 0,610 & & Valid \\
\hline & Motivasi 3 & 0,487 & & Valid \\
\hline & Motivasi 4 & 0,643 & & Valid \\
\hline & Motivasi 5 & 0,487 & & Valid \\
\hline & Motivasi 6 & 0,697 & & Valid \\
\hline \multirow{6}{*}{$\begin{array}{c}\text { Kepuasan } \\
\text { Kerja } \\
\left(\mathrm{X}_{2}\right)\end{array}$} & Kepuasan Kerja 1 & 0,508 & \multirow{6}{*}{0.238} & Valid \\
\hline & Kepuasan Kerja 2 & 0,596 & & Valid \\
\hline & Kepuasan Kerja 3 & 0,534 & & Valid \\
\hline & Kepuasan Kerja 4 & 0,548 & & Valid \\
\hline & Kepuasan Kerja 5 & 0,676 & & Valid \\
\hline & Kepuasan Kerja 6 & 0,686 & & Valid \\
\hline \multirow{6}{*}{$\begin{array}{c}\text { Disiplin } \\
\text { Kerja } \\
\left(\mathrm{X}_{3}\right)\end{array}$} & Disiplin Kerja 1 & 0,594 & \multirow{6}{*}{0.238} & Valid \\
\hline & Disiplin Kerja 2 & 0,504 & & Valid \\
\hline & Disiplin Kerja 3 & 0,428 & & Valid \\
\hline & Disiplin Kerja 4 & 0,565 & & Valid \\
\hline & Disiplin Kerja 5 & 0,551 & & Valid \\
\hline & Disiplin Kerja 6 & 0,525 & & Valid \\
\hline \multirow{6}{*}{$\begin{array}{c}\text { Kinerja } \\
(\mathrm{Y})\end{array}$} & Kinerja 1 & 0,484 & \multirow{6}{*}{0.238} & Valid \\
\hline & Kinerja 2 & 0,508 & & Valid \\
\hline & Kinerja 3 & 0,519 & & Valid \\
\hline & Kinerja 4 & 0,558 & & Valid \\
\hline & Kinerja 5 & 0,504 & & Valid \\
\hline & Kinerja 6 & 0,642 & & Valid \\
\hline
\end{tabular}

Pengujian Reliabilitas

Tabel 3. Pengujian reliabilitas

\begin{tabular}{|c|c|c|c|}
\hline \multirow[t]{2}{*}{ Variabel } & \multicolumn{2}{|c|}{ Cronbach Alfa } & \multirow[t]{2}{*}{ Resimpulan } \\
\hline & Hitung & Toleransi & \\
\hline Motivasi $\left(X_{2}\right)$ & 0,973 & \multirow{4}{*}{0,600} & Reliabel \\
\hline Repuasan Kerja (X) & 0,941 & & Reliabel \\
\hline Disiplin Kerja $(\mathrm{K})$ & 0,946 & & Reliabel \\
\hline Rinerja $(\mathrm{O})$ & 0,977 & & Reliabel \\
\hline
\end{tabular}

Tabel 2 dan tabel 3 menunjukkan bahwa instrumen yang digunakan dalam penelitian valid dan reliabel untuk menguji indikator yang ingin diketahui dalam penelitian. 
Hasil Uji Asumsi Klasik

1. Hasil Uji Normalitas

Tabel 4. Hasil Uji Normalitas Secara Serempak

Tocte of Hormality

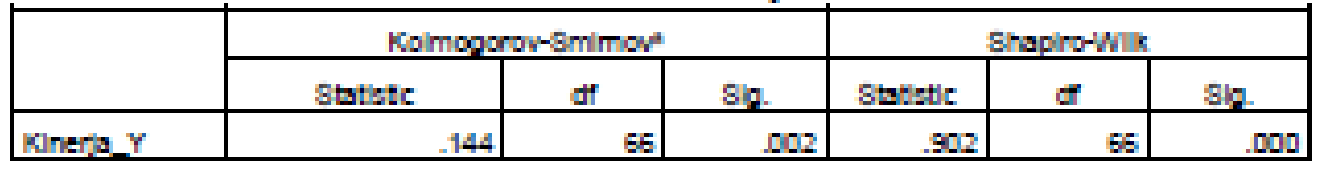

a. L efors Blphifance comstion

Sumber: Hasil Penelitian (data diolah dengan SPSS), 2015.

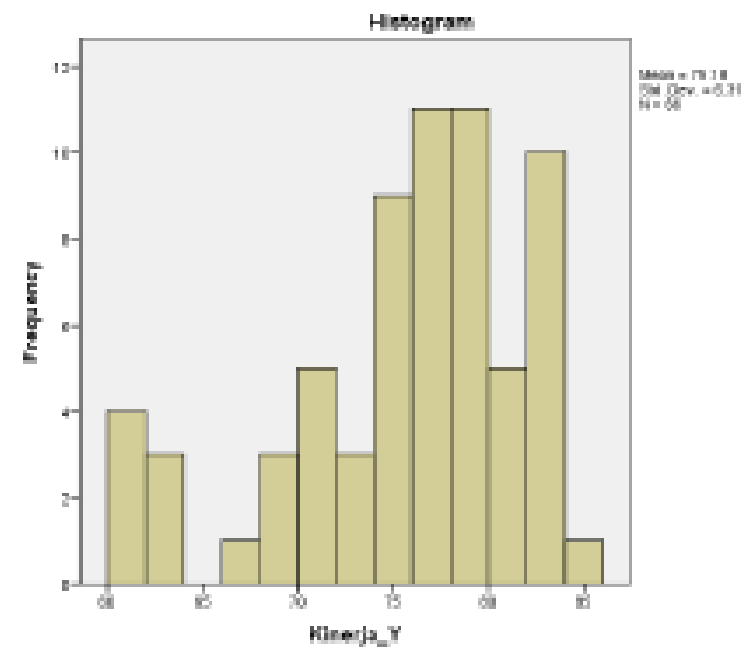

Gambar 2. Hasil uji normalitas histogram Sumber: Hasil Penelitian 2015.

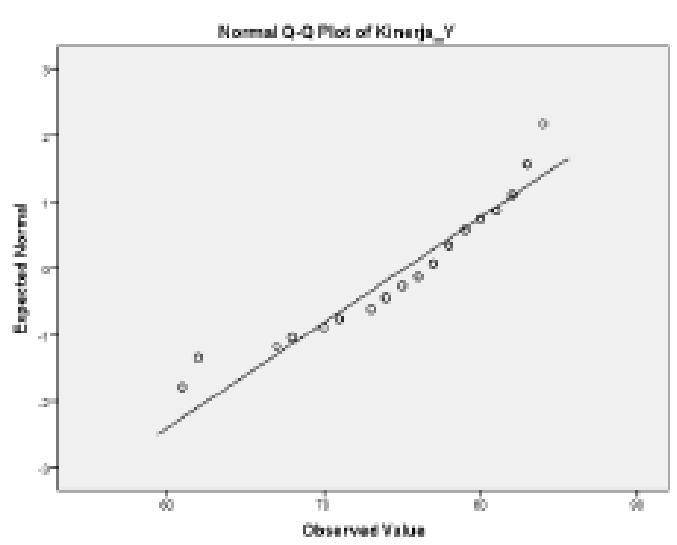

Gambar 3. Hasil uji Normalitas P Plot Sumber: Hasil Penelitian 2015. 


\section{Hasil Uji Hoteroskedasitas}

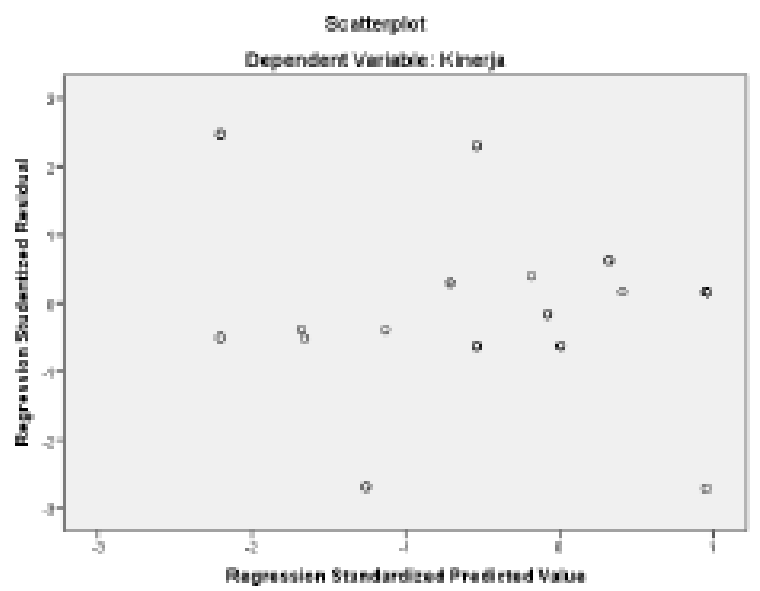

Gambar 4.Uji hoteroskedasitas.

Sumber: Hasil Penelitian (data diolah dengan SPSS), 2015.

Dari Gambar 4.3. terlihat tidak ada pola yang jelas, titik-titik juga menyebar di atas dan di bawah angka 0 pada sumbu Y, maka tidak terjadi Heteroskedastisitas.

Hipotesis pada penelitian ini adalah:

Ho : Tidak ada pengaruh yang signifikan dari motivasi, kepuasan kerja dan disiplin kerja secara bersama-sama terhadap kinerja karyawan PT Sari Dumai Sejati

$\mathrm{Ha}$ : Ada pengaruh yang signifikan dari motivasi, kepuasan kerja dan disiplin kerja secara bersama-sama terhadap kinerja karyawan PT Sari Dumai Sejati.

\section{a. Koefisien Determinasi (R2)}

Koefisien determinasi bertujuan untuk mengetahui seberapa besar variabel independen mempengaruhi variabel dependen.Koefisien determinasi terletak pada Tabel model summaryb dan tertulis pada kolom $R$ Square.Nilai koefisien determinasi dapat dilihat pada Tabel 5.

Tabel 5. Koefisien Determinasi

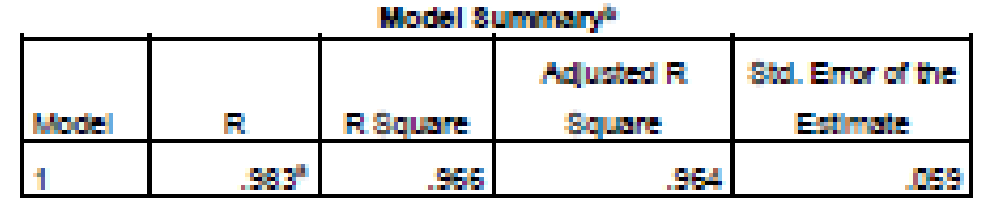

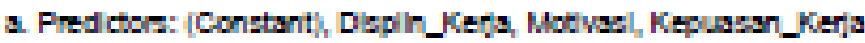

b. Dependent Variable: Rner|a

Sumber: Hasil Penelitian (data diolah dengan SPSS), 2015.

Pada Tabel 5 Nilai R sebesar 0,983 menunjukkan korelasi yang sangat erat antara motivasi, kepuasan kerja dan disipliln kerja dengan kinerja karyawan PT Sari Dumai Sejati. Dari output SPSS pada Tabel 5 memiliki nilai koefisien determinasi R Square 0,966. Artinya 96,6\% variabel dependen kinerja karyawan (Y) dipengaruhi oleh variabel independen yakni motivasi (X1), kepuasan kerja (X2) dan disiplin kerja (X3), sedangkan sisanya sebesar 3,4\% dipengaruhi oleh variabel lain yang tidak diikutsertakan dalam penelitian ini. 


\section{Uji Simultan dengan ANOVA}

Uji F dimaksudkan untuk menguji apakah variabel-variabel independen secara bersama-sama berpengaruh signifikan terhadap variabel dependen.

Tabel 6. Uji ANOVA

\begin{tabular}{|l|l|r|r|r|r|r|}
\hline \multicolumn{2}{|l|}{ Model } & Sum of Squares & df & Mean Square & F & 81g. \\
\hline \multirow{3}{*}{1} & Resreasion & 6.020 & 3 & 2.007 & 580.915 & $.000^{\circ}$ \\
\cline { 2 - 8 } & Residual & 214 & 62 & .003 & & \\
\cline { 2 - 7 } & Total & 6.234 & 65 & & & \\
\hline
\end{tabular}

a. Dependent Variabie: Kinerja

b. Predictors: (Constant), Depplin_Kerda, Motvesi, Kepuasan_Kerja

Sumber: Hasil Penelitian (data diolah dengan SPSS), 2015.

Jika probabilitasnya (nilai sig) $>0.05$ atau $\mathrm{F}$ hitung $<\mathrm{F}$ Tabel maka H0 diterima Jika probabilitasnya (nilai sig) $<0.05$ atau F hitung $>$ F Tabel maka H0 ditolak Maka F hitung > dari F tabel $(580,915>7,06)$ berarti Motivasi, Kepuasan kerja dan Disiplin kerja berpengaruh signifikan terhadap Kinerja karyawan.

Pada Tabel di atas nilai sig $=0.000<0.05$, sehingga H0 ditolak, yang berarti variabel-variabel independen secara bersama-sama berpengaruh signifikan terhadap variabel dependen.

\section{c. Persamaan pada Model Regresi}

Uji t dimaksudkan untuk menguji apakah variabel independen secara parsial berpengaruh signifikan terhadap variabel dependen.

Tabel 7. Persamaan Model Regresi

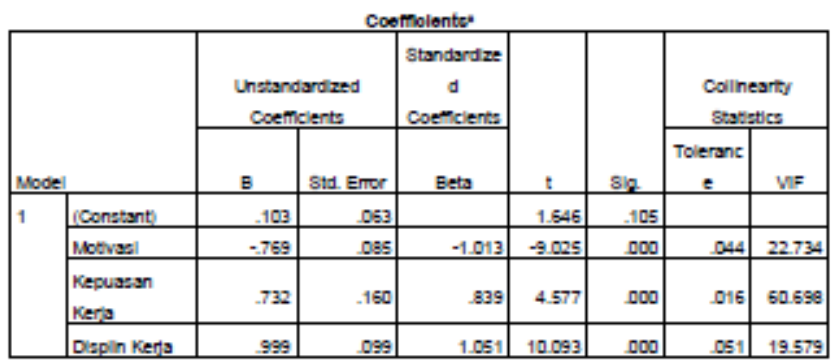

a. Dependent Varisbie: Knerio. ..............

Sumber: Hasil Penelitian (data diolah dengan SPSS), 2015.

Berdasarkan tabel 4.17 diperoleh persamaan regresinya adalah

$\mathrm{Y}=\mathrm{a}+\mathrm{b} 2 \mathrm{X} 2+\mathrm{b} 2 \mathrm{X} 2+\mathrm{b} 3 \mathrm{X} 3+\mathrm{e}$

$\mathrm{Y}=0,103-0,769 \cdot \mathrm{X} 1+0,732 \cdot \mathrm{X} 2+0,999 \cdot \mathrm{X} 3$

Artinya :

1) Konstanta sebesar 0,103 menyatakan bahwa jika variabel independen dianggap tetap (konstan).

2) Koefisien regresi Motivasi 0,769 menyatakan bahwa setiap peningkatan motivasi karyawan sebesar 1 akan menurunkan kinerja karyawan sebesar 0,769 .

3) Koefisien regresi kepuasan kerja 0,732 menyatakan bahwa setiap peningkatan kepuasan kerja karyawan sebesar 1 akan meningkatkan kinerja karyawan sebesar 0,732 .

4) Koefisien regresi disiplin kerja 0,999 menyatakan bahwa setiap peningkatan disiplin kerja karyawan sebesar 1 akan meningkatkan kinerja karyawan sebesar 0,999 . 
5) Variabel independen yang memberikan pengaruh paling besar terhadap kinerja karyawan adalah Disiplin Kerja (X3)

6) Dengan nilai koefisien terbesar dibandingkan variabel lainnya yakni 0,999. Sedangkan variabel independen yang memberikan pengaruh paling kecil terhadap kinerja karyawan adalah Motivasi (X1) dengan nilai koefisien terkecil dibandingkan variabel lainnya yakni - 0,769.

\section{Simpulan}

Berdasarkan pada hasil penjelasan sebelumnya, maka penelitian dapat disimpulkan Dari hasil analisis dan pembahasan pada bab sebelumnya, penulis menyimpulkan bahwa: kinerja karyawan PT Sari Dumai Sejati 96,4\% dipengaruhi oleh motivasi, kepuasan kerja dan disiplin kerja, sisanya 3,6\% dipengaruhi faktor lain yang tidak diteliti pada penelitian ini. Kepuasan kerja,dan disiplin kerja berpengaruh terhadap kinerja karyawan di PT Sari Dumai Sejati berdasarkan nilai perbandingan sig probabilitas dengan nilai alpha penelitian. Disiplin kerja merupakan faktor yang paling besar mempengaruhi kinerja karyawan dibandingkan faktor lainnya yakni 0,999.Sedangkan faktor yang memberikan pengaruh yang paling kecil terhadap kinerja karyawan adalah Motivasi (-0,769).Variabel independen yang memiliki korelasi positif terhadap kinerja karyawan adalah kepuasan kerja dan Disiplin kerja sedangkan yang memiliki korelasi negatif terhadap kinerja karyawan adalah motivasi kerja. Berarti meningkatnya motivasi, kepuasan kerja dan disiplin kerja akan meningkatkan kinerja karyawan.

\section{Daftar Pustaka}

Devi, Eva Kris Diana, 2009, Analisis Pengaruh Kepuasan Kerja dan MotivasiTerhadap Kinerja Karyawan dengan Komitmen Organisasional sebagai Variabel Intervening, Tesis Magister Manajemen, Universitas Diponegoro, Semarang.

Fathoni, Aburrahmat, 2009, Organisasi dan Manajemen Sumber Daya Manusia, Penerbit Rineka Cipta, Jakarta.

Hasibuan, Malayu, 2011, Manajemen Sumber Daya Manusia, Edisi Revisi, Penerbit Bumi Aksara, Jakarta.

Hernowo, Narmodo, 2008. "Pengaruh Motivasi, dan Disiplin Kerja Terhadap Kinerja Badan Kepegawaian Daerah Kabupaten Wonogiri", Journal Daya Saing.pdf, Diakses Agustus 2015.

Listianto, Tony, 2006. "Pengaruh Motivasi, Kepuasan dan Disiplin Kerja Terhadap Kinerja Pegawai (Studi Kasus di Lingkungan Pegawai Kantor PDAM Kota Surakarta)", Solo, Tesis Magister Ilmu Manajemen Universitas Muhammadiyah Surakarta.

Santoso, Singgih, 2015. Menguasai Statistik Multivariat, Penerbit PT Elex Media Jakarta, Komputindo.

Sekaran, Uma, 2006, Research Methods For Business, Metodologi Penelitian Untuk Bisnis, Edisi Ke-4, Penerbit Salemba Empat, Jakarta 
Siagian, Sondang, 2009, Kiat Meningkatkan Produktivitas Kerja, Cetakan Kedua, Penerbit Rineka Cipta, Jakarta.

Timothy, Stephen, 2015, Perilaku Organisasi, Edisi Ke-16, Penerbit Salemba Empat, Jakarta Selatan. 